\title{
Characterizing alterations in the pulmonary surfactant system in a rat model of Pseudomonas aeruginosa pneumonia
}

\author{
J. Vanderzwan*, L. McCaig*, S. Mehta**, M. Joseph***, \\ J. Whitsett+, D.G. McCormack**, J.F. Lewis**
}

\begin{abstract}
Characterizing alterations in the pulmonary surfactant system in a rat model of Pseudomonas aeruginosa pneumonia. J. Vanderzwan, L. McCaig, S. Mehta, M. Joseph, J. Whitsett, D.G. McCormack, J.F. Lewis. CERS Journals Ltd 1998.

ABSTRACT: Bacterial pneumonia remains a significant cause of patient morbidity and mortality worldwide. Pulmonary surfactant serves to maintain homeostasis in the lung through the maintenance of alveolar stability and the regulation of the alveolar immune response. The purpose of this study was to characterize the lung injury and associated surfactant alterations in a rat model of acute Pseudomonas aeruginosa pneumonia.

Pneumonia was induced in male Sprague-Dawley rats via intratracheal injection of $0.2 \mathrm{~mL}$ phosphate-buffered saline (PBS) containing $P$. aeruginosa $\left(6 \times 10^{8}\right.$ colonyforming units $\cdot \mathrm{mL}^{-1}$ ). Control animals received $0.2 \mathrm{~mL}$ sterile PBS.

Twenty-four hours after inoculation, the pneumonia group (PN) exhibited clinical signs of pneumonia including deficits in gas exchange, leukopenia and elevated arterial lactate levels. Morphological assessment confirmed the presence of pneumonia with airspaces filled with polymorphonuclear cells. Lung homogenate analysis demonstrated evidence of bacterial colonization of pneumonic lung tissue. Lung compliance was also significantly lower in the PN group. Lung lavage analysis of PN rats revealed the pooled surfactant levels to be lower and the surfactant function reduced compared to control rats. Surfactant composition was also found to be altered in PN rats.
\end{abstract}

These results demonstrate that in Pseudomonas aeruginosa pneumonia, the pulmonary surfactant system is both poorly functioning and reduced in quantity. These alterations may contribute to the lung dysfunction characteristic of this disorder. Eur Respir J 1998; 12: 1388-1396.
Depts of *Physiology, **Medicine and ***Pathology, Lawson Research Institute, St Joseph's Health Centre, University of Western Ontario, London, Ontario, Canada. +Dept of Paediatrics, University of Cincinnati, College of Medicine, Cincinnati, Ohio, USA.

Correspondence: J.F. Lewis

Dept of Medicine

Lawson Research Institute

St Joseph's Health Centre

268 Grosvenor St.

London

Ontario

Canada N6A 4V2

Fax: 15196466064

Keywords: Acute lung injury, acute respiratory distress syndrome, inflammation, pneumonia, Pseudomonas aeruginosa, pulmonary surfactant

Received: December 191997

Accepted after revision August 11998

Supported by grants from the Ontario Thoracic Society and the Medical Research Council of Canada.
Nosocomial bacterial pneumonia occurs in up to $5 \%$ of hospitalized patients [1]. One of the most common causative agents is the Gram-negative bacterial organism Pseudomonas aeruginosa [2]. Owing to strains of this organism being resistant to most antibiotics, the mortality of this illness remains relatively high, ranging 36-81\% [2].

Pulmonary surfactant is the phospholipid-protein material lining the inner surface of the alveolus and is primarily responsible for surface tension reduction at the air-liquid interface [3]. This biophysical function prevents alveolar collapse and permits breathing with minimal effort. In addition, surfactant is the surface that antigens contact during inhalation. Recently, a variety of in vitro studies have implicated surfactant in the alveolar immune response to bacterial infection. In these studies, surfactant and its associated proteins have been observed to inhibit cytokine release from alveolar macrophages (AM) $[4,5]$, inhibit interferon- $\boldsymbol{\gamma}$-stimulated monocyte activation [6] and inhibit lymphocyte proliferation [7]. In addition to these antiinflammatory effects, surfactant-associated proteins have also been shown to have important antibacterial actions through the augmentation of AM chemotaxis [8-10], the regulation of AM production of toxic oxygen metabolites $[8,11,12]$ and enhancing the phagocytosis of invading pathogens by AMs $[8,13,14]$. In vivo observations also suggest that pulmonary surfactant may be important in humans with pneumonia. Studies examining bronchoalveolar lavage (BAL) fluid obtained from patients with both Gram-positive and Gram-negative pneumonia have demonstrated alterations in the endogenous surfactant systems $[15,16]$.

Further evidence suggesting that surfactant may play a role in the lung dysfunction associated with pneumonia stems from the observed surfactant alterations in patients with acute respiratory distress syndrome (ARDS), which is associated with similar alterations in lung mechanics and in the surfactant system, as observed in pneumonia $[17,18]$. Several studies have shown that these changes contribute to the lung dysfunction observed in ARDS and exogenous surfactant has shown promise as a therapeutic modality in these patients $[3,17,19]$.

Based on this evidence, it was hypothesized that the administration of exogenous surfactant may constitute an effective treatment strategy for patients with acute bacterial pneumonia. Before testing this hypothesis, however, it is important to characterize extensively the changes in the endogenous surfactant system in bacterial pneumonia and determine whether these changes contribute to the lung dysfunction associated with this disorder. The objective of 
this study, therefore, was to establish a clinically relevant animal model of acute $P$. aeruginosa pneumonia and characterize the alterations in the pulmonary surfactant system in this model. This information will provide further insight into the role of the surfactant system in bacterial pneumonia and may ultimately lead to treatment strategies involving exogenous surfactant.

\section{Materials and methods}

\section{Animals}

Adult male Sprague-Dawley rats (Charles River, Constant, Quebec, Canada), weighing approximately 350-450 $\mathrm{g}$, were used for these experiments. Experimental procedures complied with standards outlined by the Canadian Council on Animal Care and the Animals for Research Act of Ontario.

\section{Study design}

Rats were intratracheally instilled with a bacterial suspension of $P$. aeruginosa. Control rats were instilled with a similar volume of sterile saline. Twenty-four hours after inoculation, arterial blood gases and blood cell counts were measured and rats were sacrificed for subsequent measures of lung compliance and the analysis of the pulmonary surfactant system. Surfactant quantity, composition and function were characterized. Separate animals were studied for morphological assessment and bacterial colonization of lung tissue.

\section{Preparation of bacterial inoculum}

Each volume of inoculum of $P$. aeruginosa (ATCC strain 27853) was prepared fresh daily from an overnight blood agar culture plate. In brief, colonies were isolated from the culture plate and resuspended in sterile phosphate-buffered saline (PBS), $\mathrm{pH}$ 7.2. The optical density of the bacterial suspension was measured using a Vitek colorimeter (Hach, Hazlewood, MO, Colorado, USA) and adjusted to a concentration approximating to a turbidity index of 2 MacFarland standard $\left(6.0 \times 10^{8}\right.$ colony-forming units. $\left.\mathrm{mL}^{-1}\right)$.

The exact concentration of viable bacteria was quantified for each inoculum by preparing duplicate serial dilutions of the bacterial suspension in $0.9 \% \mathrm{NaCl}$. Subsequently, $50-\mu \mathrm{L}$ aliquots of the $10^{6}$-fold dilution were spread in duplicate on $7 \%$ sheep blood agar plates, which were then incubated at $35^{\circ} \mathrm{C}$ for $24 \mathrm{~h}$. Following incubation, the number of pseudomonas colonies was counted on each plate, an average from the two plates was obtained, and a more accurate concentration in $\mathrm{cfu} \cdot \mathrm{mL}^{-1}$ was calculated. All materials used for the above procedures were sterile.

\section{Animal preparation}

Rats were acclimatized to the laboratory environment for 1 week before experimentation. During this acclimati- zation period, rats were allowed free access to food and water. Rats were placed in an anaesthesia chamber and were exposed to $4 \%$ halothane in $100 \%$ oxygen until general anaesthesia with adequate spontaneous respiration was attained. The rats were then removed from the chamber, weighed, placed on the surgical table and attached to a nose-cone set-up to maintain anaesthesia under $2 \%$ halothane in $100 \%$ oxygen. An incision was made in the anterior neck region and PE-50 tubing was used to cannulate both the right external jugular vein and the right carotid artery. These catheters were then routed subcutaneously to the dorsal area of the neck and attached to a swivel and harness system to allow the rat free movement within the cage.

\section{Induction of pneumonia}

After preparation, animals were randomly assigned to a pneumonia (PN) or sham control group. After cannulation of the animal and before recovery from anaesthesia, the trachea was isolated and punctured with a 22-gauge angiocatheter and the angiocatheter sheath was inserted to a point just above the carina. A $0.2-\mathrm{mL}$ bolus of the bacterial suspension was instilled intratracheally through the angiocatheter to animals in the PN group. Animals of the control group were instilled with a similar volume of sterile saline to account for any effects of the introduction of fluid into the airspace. Instillation of these fluid volumes was followed by a $0.5-\mathrm{mL}$ intratracheal bolus of air, in order to facilitate distribution of the inoculum to the periphery of the lungs. The angiocatheter was then removed and the tracheal puncture point covered with gelfoam (Pharmacia and UpJohn, Bridgewater, NJ, USA). The incision in the anterior neck region was closed using 4-0 silk suture and each rat was placed in a cage to recover.

\section{Animal recovery and monitoring}

Rats were allowed to recover in their cage with their swivel system attached, allowing free movement and access to food and water ad libitum. Postoperatively all rats received a continuous $i$.v. infusion of saline at a rate of 0.5 $\mathrm{mL} \cdot 100 \mathrm{~g}^{-1} \cdot \mathrm{h}^{-1}$ containing $2 \mu \mathrm{g} \cdot \mathrm{mL}^{-1}$ fentanyl for continuous analgesia. A continuous arterial infusion of heparinized $\left(2 \mathrm{U} \cdot \mathrm{mL}^{-1}\right)$ saline was also administered at a rate of $0.5 \mathrm{~mL} \cdot 100 \mathrm{~g}^{-1} \cdot \mathrm{h}^{-1}$ to maintain line patency.

Arterial blood samples were obtained $24 \mathrm{~h}$ after tracheal inoculation. Blood gases were obtained using an ABL 500 blood gas analyser (Radiometer, Copenhagen, Denmark) and arterial lactate levels were measured using a YSI 2300 STAT Plus glucose/lactate analyser (Radiometer). Mean arterial blood pressure (MAP) and cardiac frequency $(f \mathrm{C})$ were monitored through the arterial line via a blood pressure monitor (Honeywell, Minneapolis, MN, USA). Respiratory frequency $(f \mathrm{R})$ was also recorded. Additional arterial blood samples $(0.25 \mathrm{~mL})$ were obtained just before killing for an automated complete blood cell count analysis (Coulter JT3, Miami, Florida, USA).

Following the 24-h monitoring period and blood sampling as described above, general anaesthesia of the animal was induced by an i.v. injection of a 1-mL bolus of $2.5 \%$ sodium thiopental. An abdominal incision was made and 
rats were killed by transection of the descending aorta. Rats then underwent either lung compliance measurements with a subsequent whole-lung lavage for surfactant analysis or a whole-lung homogenization for bacterial counts.

\section{Morphological assessment}

Three animals within each group were studied for morphological assessment, with the pathologist blinded to the rat's experimental condition. The heart and lungs were removed en bloc from the animals and immediately placed in $10 \%$ neutral-buffered formalin fixative. Inflation of the lungs was achieved by tracheobronchial perfusion using a 22-gauge butterfly needle connected to a syringe filled with $5 \mathrm{~mL}$ formalin. Following overnight fixation, the lobes of the lungs were separated and grossly examined and representative sections were taken from each lobe for histological evaluation. The sections were embedded in paraffin and $5 \mu \mathrm{m}$ sections were stained with haematoxylin and eosin.

\section{Lung compliance measures}

In separate groups of rats, immediately after the animals were killed, the chest wall was removed in order to visualize both lungs and a tracheostomy was performed for endotracheal tube insertion. Rats were then placed in a vacuum chamber for approximately $1 \mathrm{~min}$ to evacuate residual air within the lungs. Once removed from the chamber, the endotracheal tube was attached to a U-shaped manometer and the lungs were inflated in $2 \mathrm{cmH}_{2} \mathrm{O}$ pressure increments using a glass syringe. A $20 \mathrm{~s}$ pause was performed at each pressure interval to ensure adequate filling. The corresponding volumes administered were recorded from the syringe at each pressure, up to a maximum pressure of $26 \mathrm{cmH}_{2} \mathrm{O}$. Lungs were then deflated in the same pressure increments to a minimum pressure of 0 $\mathrm{cmH}_{2} \mathrm{O}$.

\section{Lung lavage analysis}

Ten millilitres of $0.9 \% \mathrm{NaCl}$ was infused into the lungs via the endotracheal tube, withdrawn and reinfused twice. This procedure was repeated a total of four times with the final total volume of crude alveolar wash (CAW) recorded [20].

Ten millilitres of the CAW was stored for total surfactant pool size analysis, surfactant-associated protein measurements and total protein measurements. The remainder of the CAW was centrifuged in order to separate the alveolar surfactant into different aggregate subfractions as described previously $[21,22]$. In brief, the CAW sample was centrifuged for $10 \mathrm{~min}$ at $150 \times g$ yielding a pellet $(\mathrm{P} 1)$ containing primarily cellular debris. The resulting supernatant was then centrifuged for $15 \mathrm{~min}$ at $40,000 \times g$ yielding a pellet containing the large aggregate (LA) surfactant subfraction and a supernatant containing the small aggregate (SA) surfactant subfraction. P1 and LA pellets were each resuspended in $2.2 \mathrm{~mL} 0.9 \% \mathrm{NaCl}$ for further analysis.
Aliquots of CAW, P1 pellet, and LA and SA fractions were extracted using the chloroform-methanol procedure described by BLIGH and DYER [23]. This procedure was performed in order to isolate lipids and remove any proteins, phospholipases or proteases from the lavage which may have interfered with our subsequent surfactant quantification procedures. Following this extraction step, samples were then dried under nitrogen and disaturated phospholipids (DSPL), the main functional lipid component of surfactant, were isolated and measured as described previously [24]. In brief, $0.5 \mathrm{~mL} 0.5 \%$ (w/v) osmium tetroxide in $\mathrm{CCl}_{4}$ was added to the dried sample tube, followed by an additional period of drying under nitrogen. A chloroform-methanol (20:1) solution was used to wash an alumina column (Sep-Pak Alumina N Cartridges; Waters, Millford, MA, USA). This solution was then added to the samples and passed through the washed column. The DSPL component was eluted from the column using a chloroform-methanol-ammonium hydroxide solution (35: $15: 1, \mathrm{v} / \mathrm{v} / \mathrm{v})$.

The total DSPL phosphorus content of each eluent was then quantified using a modification of the method described previously by Ducк-CHоNG [25]. The total phosphorus contents of each of the CAW, P1, as well as the LA and SA-containing subfractions were also measured before the DSPL isolation procedure using a similar method. In brief, $100 \mu \mathrm{L} 10 \%$ magnesium nitrate in methanol was added to the samples. Samples were then dried under air and subsequently ashed on an electric rack for approximately $1 \mathrm{~min}$. Ashing was followed by the addition of 1 $\mathrm{mL} 1 \mathrm{M} \mathrm{HCl}$ and subsequent heating for $15 \mathrm{~min}$ at $95^{\circ} \mathrm{C}$. After cooling, a $66-\mu \mathrm{L}$ aliquot of each sample was added to the well of a 96-well plate and $134 \mu \mathrm{L}$ of a dye reagent consisting of $4.2 \%$ ammonium molybdate in $4.5 \mathrm{M} \mathrm{HCl}$ with $0.3 \%$ malachite green was added. Sample absorbance at $650 \mathrm{~nm}$ was then measured using a MKII Titretek Multiskan enzyme-linked immunosorbent assay (ELISA) plate reader and compared with reference standards. The total CAW protein content was quantified using the method of Lowry et al. [26] using bovine serum albumin (BSA) as a standard.

\section{Assessment of surface activity}

Aliquots of the isolated LA surfactant fraction were resuspended in $1.5 \mathrm{mM} \mathrm{CaCl}_{2}$ in $0.9 \%$ saline to a concentration of $1 \mathrm{mg}$ phospholipid. $\mathrm{mL}^{-1}$. Surface activity was assessed using a pulsating bubble surfactometer (Electronetics Corporation, Buffalo, NY, USA) as described previously [27]. In brief, a bubble was created in the suspension containing the LA surfactant fraction. After $10 \mathrm{~s}$ of adsorption, the bubble was pulsed for a period of 5 min between a maximum radius of $0.55 \mathrm{~mm}$ and a minimum radius of $0.44 \mathrm{~mm}$ at a rate of 20 pulsations $\cdot \mathrm{min}^{-1}$ and a temperature of $37^{\circ} \mathrm{C}$. Pressure was monitored across the air-liquid interface using a pressure transducer and surface tensions at the minimum bubble radius $\left(\mathrm{R}_{\mathrm{min}}\right)$ were calculated.

\section{Surfactant protein measures}

A previously established ELISA [20, 22, 28, 29] was used to measure rat surfactant-associated protein (SP)-A 
and rat SP-B in the CAW of both control and PN animals. For SP-A, wells were coated with a $1 / 100$ dilution of concentrated mouse lavage in $0.1 \mathrm{NaHCO}_{3}$. Wells were blocked with $5 \%$ human serum in $82 \mathrm{~b}(0.15 \mathrm{M} \mathrm{NaCl}, 0.01$ tris-hydroxymethyl-amino methane (Tris), $\mathrm{pH} 7.4$, and 5 $\mu \mathrm{g} \cdot \mathrm{mL}^{-1}$ of BSA). Samples and standards were preincubated overnight at $37^{\circ} \mathrm{C}$ in a $1 / 8,000$ dilution of rabbit antimouse SP-A in $82 \mathrm{~b}$ with $5 \%$ human serum and $0.5 \%$ Nonidet P-40. The samples and standards were then incubated in the coated wells for 1-2 h, and the wells were washed and incubated with goat antirabbit immunoglobulin $\mathrm{G}(\mathrm{IgG})$ conjugated to peroxidase (Calbiochem, La Jolla, California, USA). After washing, colour was developed using $100 \mu \mathrm{L} 0.065 \mathrm{M} \mathrm{NaKPO}_{4}, \mathrm{pH} 6.3$, containing $0.017 \mathrm{M}$ citric acid, $0.05 \% \mathrm{H}_{2} \mathrm{O}_{2}$, and $5 \mathrm{mg} \cdot \mathrm{mL}^{-1} o$-phenylenediamine. The colour reaction was stopped using $50 \%$ sulphuric acid and the absorbance at $492 \mathrm{~nm}$ was determined.

For SP-B determination, wells were incubated with standard purified bovine SP-B (0.5-10 ng) or sample, a polyclonal antirabbit SP-B antibody and a secondary antirabbit IgG antibody conjugated to peroxidase. All samples were analysed simultaneously in a single assay. Colour was developed and measured as described above for SP-A.

\section{Phospholipid composition}

Using a separate group of animals, total CAW samples were centrifuged for $10 \mathrm{~min}$ at $150 \times g$ and cellular debris was removed. The resulting supernatant was extracted using the method described by BLIGH and DYER [23] and dried slowly under nitrogen. The remaining pellet was dissolved in $2 \mathrm{~mL}$ chloroform. Phosphorus measurements were made on aliquots of the chloroform solution using a modification of the method described by Duck-CHong [25]. Subsequently, samples were dried under nitrogen and the pellet was dissolved in chloroform to a total phospholipid concentration of $0.2 \mathrm{mg} \cdot \mathrm{mL}^{-1}$. Phospholipid compositions were performed using thin-layer chromatography (TLC) as described previously [22]. In brief, $50 \mu \mathrm{L}$ aliquots of the sample and $5 \mu \mathrm{L}$ aliquots of reference standards were spotted on linear-K silica gel TLC (Whatman, Maidstone, UK) plates and developed using an ethanol-triethylaminechloroform-water developing solvent (35:34:30:8, v/v/v/v). After reference standards were visualized with DittmerLester phosphorus spray [30], the corresponding phospholipids were scraped from sample lanes and phosphorus was measured using the Duck-CHong assay [25]

\section{Bacterial counts}

The whole lungs of animals used for bacterial analysis were aseptically removed en bloc from the chest cavity and the trachea and large airways were dissected. The remaining lung tissue was then weighed and suspended in $3 \mathrm{~mL}$ sterile $10 \mathrm{mM}$ HEPES buffer containing $0.32 \mathrm{M}$ sucrose. Using a T25 rotor-stator tissue homogenizer (Janke and Kunkel, Staufen, Germany), the lungs from each animal were homogenized and the total volume of lung homogenate was recorded. Serial 10 -fold dilutions using $0.9 \% \mathrm{NaCl}$ were prepared in duplicate from the original lung homogenate fraction, up to a dilution factor of 1:10,000. Then, 50- $\mu \mathrm{L}$ aliquots of each dilution were then plated in duplicate on $7 \%$ sheep blood agar and incubated at $35^{\circ} \mathrm{C}$ for $24 \mathrm{~h}$. Following incubation, the culture plates were examined for bacterial growth and pseudomonas colonies were visually identified and counted. An average from the two plates was determined and, using the dilution factor, the total bacterial load in the lungs was calculated and expressed as percentage recovery from the initial input. All materials used in the above procedure were sterile.

\section{Data analysis}

The alveolar-arterial oxygen tension gradient $\left(\mathrm{PA}-\mathrm{a}, \mathrm{O}_{2}\right)$ was found using the alveolar gas equation to determine alveolar oxygen tension $\left(\mathrm{PA}, \mathrm{O}_{2}\right): P \mathrm{~A}, \mathrm{O}_{2}=\left(P \mathrm{~B}-\mathrm{PH}_{2} \mathrm{O}\right) \times$ $F \mathrm{I}, \mathrm{O}_{2}-\left(P \mathrm{~A}, \mathrm{CO}_{2} / \mathrm{R}\right)$, where $P \mathrm{~B}$ is barometric pressure, $P_{2} \mathrm{O}$ is the partial pressure of water vapour, $F \mathrm{I}, \mathrm{O}_{2}$ is the inspired $\mathrm{O}_{2}$ fraction, $P \mathrm{~A}, \mathrm{CO}_{2}$ is the mean alveolar carbon dioxide tension (assumed to be equal to arterial $\mathrm{CO}_{2}$ tension), and $\mathrm{R}$ is the respiratory quotient (assumed to be equal to 0.8).

All data are expressed as means \pm SEM. Values obtained from control and PN groups were compared using an unpaired Student's t-test (two-tailed) and a probability level of $p<0.05$ was considered to be statistically significant.

\section{Results}

\section{Physiological parameters}

Table 1 shows mean values for body weight, $P \mathrm{~A}-\mathrm{a}, \mathrm{O}_{2}, f \mathrm{C}$, $f \mathrm{R}$, MAP, arterial lactate and white blood cell counts (WBC) for both the control and PN groups $24 \mathrm{~h}$ after tracheal instillation. There was significantly altered gas exchange in the pneumonic animals compared with the

Table 1. - Physiological parameters of sham-treated control and pneumonic (PN) rats $24 \mathrm{~h}$ after intratracheal instillation of sterile phosphate-buffered saline and Pseudomonas aeruginosa, respectively

\begin{tabular}{|c|c|c|}
\hline & Control & PN \\
\hline Body weight $\mathrm{g}$ & $\begin{array}{r}388 \pm 8 \\
(18)\end{array}$ & $\begin{array}{r}395 \pm 7 \\
(24)\end{array}$ \\
\hline$P_{\mathrm{a}, \mathrm{O}_{2}} \mathrm{mmHg}$ & $\begin{array}{c}83.6 \pm 2.5 \\
(17)\end{array}$ & $\begin{array}{c}69.8 \pm 1.6^{*} \\
(23)\end{array}$ \\
\hline$P \mathrm{~A}-\mathrm{a}, \mathrm{O}_{2}$ & $\begin{array}{c}16.6 \pm 1.7 \\
(17)\end{array}$ & $\begin{array}{c}29 \pm 1.7 * \\
(23)\end{array}$ \\
\hline$f \mathrm{R}$ breaths $\cdot \mathrm{min}^{-1}$ & $\begin{array}{r}97 \pm 3 \\
(17)\end{array}$ & $\begin{array}{c}120 \pm 5^{*} \\
(24)\end{array}$ \\
\hline$f \mathrm{C}$ beats $\cdot \mathrm{min}^{-1}$ & $\begin{array}{r}333 \pm 8 \\
(17)\end{array}$ & $\begin{array}{r}323 \pm 7 \\
(23)\end{array}$ \\
\hline MAP $\mathrm{mmHg}$ & $\begin{array}{r}118 \pm 3 \\
(17)\end{array}$ & $\begin{array}{c}106 \pm 2 * \\
(24)\end{array}$ \\
\hline Lactate $\mathrm{mmol} \cdot \mathrm{L}^{-1}$ & $\begin{array}{c}0.501 \pm 0.027 \\
(17)\end{array}$ & $\begin{array}{c}0.676 \pm 0.034 * \\
(22)\end{array}$ \\
\hline WBC $\times 10^{9}$ cells $\cdot \mathrm{mL}^{-1}$ & $\begin{array}{c}11.5 \pm 1.2 \\
(10)\end{array}$ & $\begin{array}{c}6.6 \pm 0.8^{*} \\
\text { (7) }\end{array}$ \\
\hline
\end{tabular}

Values are means \pm sEM. Numbers in parentheses are numbers of rats. $P_{\mathrm{a}, \mathrm{O}_{2}}$ : arterial oxygen tension; $P_{\mathrm{A}-\mathrm{a}, \mathrm{O}_{2}}$ : alveolar-arterial oxygen tension gradient; $f \mathrm{R}$ : respiratory frequency; $f \mathrm{C}$ : cardiac frequency; MAP: mean arterial pressure; WBC: white blood cell counts*: $\mathrm{p}<0.05$ versus control animals. $(1 \mathrm{mmHg}=0.133$ $\mathrm{kPa}$.) 
control rats. This was characterized by lower arterial oxygen tension $\left(\mathrm{Pa}, \mathrm{O}_{2}\right)$ values, elevated $P \mathrm{~A}-\mathrm{a}, \mathrm{O}_{2}$ gradients and higher $f \mathrm{R}$ in the $\mathrm{PN}$ group $(\mathrm{p}<0.05)$. There were no significant differences in $\mathrm{Pa}_{\mathrm{a}} \mathrm{CO}_{2}$ values between the two groups (data not shown).
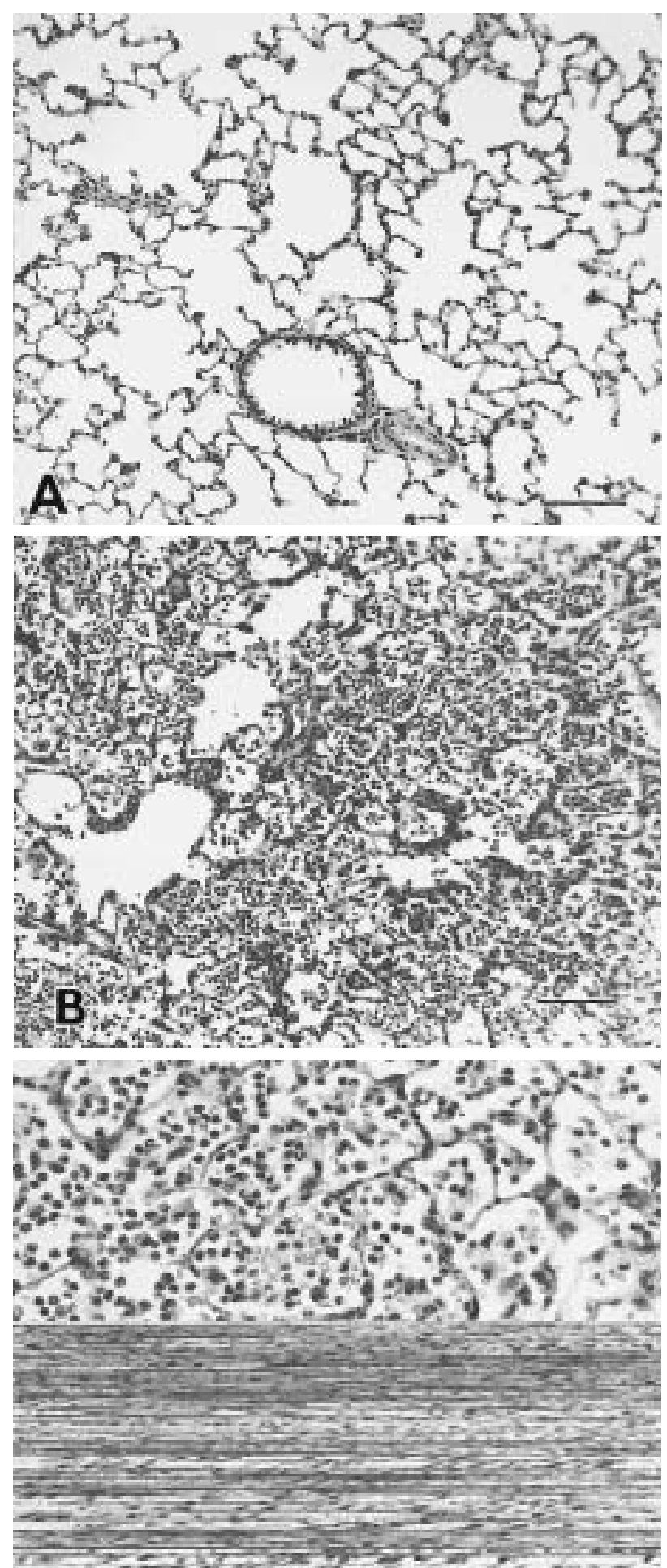

Fig. 1. - Morphology of haematoxylin and eosin-stained rat lungs. A) Sham-treated control rat lungs ( $24 \mathrm{~h}$ after instillation of phosphate-buffered saline) showing normal airspaces and a bronchiole (bar=100 $\mu \mathrm{m}$ ). B, C) Pneumonic rat lung (24 h after instillation of Pseudomonas aeruginosa) showing abundant polymorphonuclear cells and some red cells filling the airspaces. (Internal scale bars $=100 \mu \mathrm{m}$.)
Modest haemodynamic changes were also evident in the PN group compared with the control group just before killing. Although $f \mathrm{C}$ was comparable between groups, the MAP was slightly, albeit significantly, lower in the pneumonia group $(\mathrm{p}<0.05)$. PN rats also had significantly higher lactate levels than control rats and significantly lower WBC counts $(\mathrm{p}<0.05)$.

\section{Morphological assessment}

The morphological appearance of lungs from animals in both the control and PN groups are shown in figure 1 . The control animals showed normal lungs with no evidence of injury. In PN animals, there was evidence of acute bronchopneumonia with the airspaces filled with abundant polymorphonuclear cells, some red cells, and fibrin.

\section{Pressure-volume curves}

Static lung compliance was determined via measurements of pressure-volume curves after killing (fig. 2). This graph shows that the lung compliance of PN rats was significantly different to the compliance measured in the control rats. The maximum recruitable volume $\left(V_{\max }\right)$ at the highest inflation pressure $\left(26 \mathrm{cmH}_{2} \mathrm{O}\right)$ was significantly lower in the PN rats $(\mathrm{p}<0.05)$. On the deflation limb of the curve, the volume remaining in the lungs at a pressure of $6 \mathrm{cmH}_{2} \mathrm{O}\left(V_{6}\right)$ was also significantly lower in the PN group than in control animals $(\mathrm{p}<0.05)$, as were values at each transpulmonary pressure on the deflation limb of the curve. In addition, a decreased hysteresis was observed in rats instilled with pseudomonas compared with the control animals.

\section{Surfactant analysis}

The total phospholipid pool sizes of CAW, cellular pellet (P1), and both LA and SA surfactant fractions were

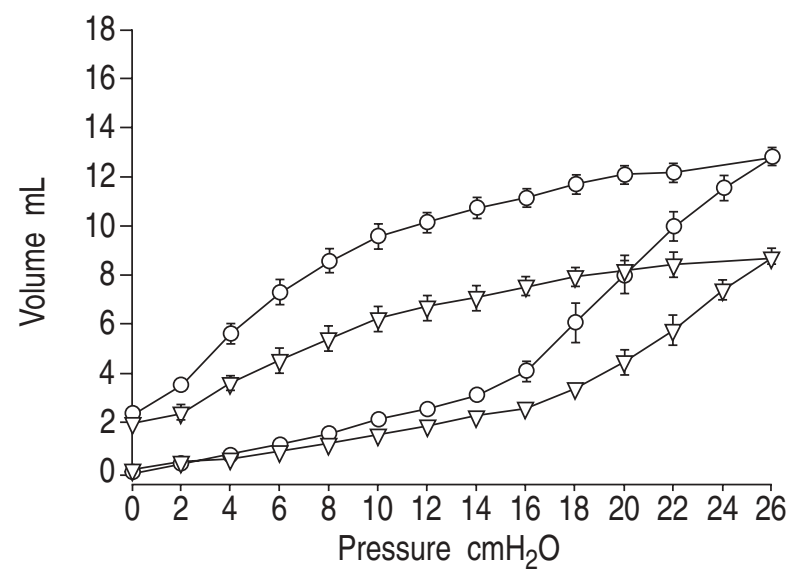

Fig. 2. - Pressure-volume curves for sham-treated control $(\mathrm{o}, \mathrm{n}=5)$ and pneumonic $(\mathrm{PN} ; \nabla, \mathrm{n}=4)$ rats, obtained $24 \mathrm{~h}$ after intratracheal instillation of sterile phosphate-buffered saline (PBS) or Pseudomonas aeruginosa, respectively. All measurements were conducted after the animal was killed, the chest wall was removed and residual air in the lungs evacuated. All volumes on the deflation limb of the curve, specifically at maximal pressure and $6 \mathrm{cmH}_{2} \mathrm{O}$, were significantly lower in PN rats than in control rats $(\mathrm{p}<0.05)$. In addition, on the inflation limb of the curve, volumes were significantly lower for pneumonic rats at 14 $26 \mathrm{cmH}_{2} \mathrm{O}(\mathrm{p}<0.05)$. Values are expressed as means \pm SEM. 


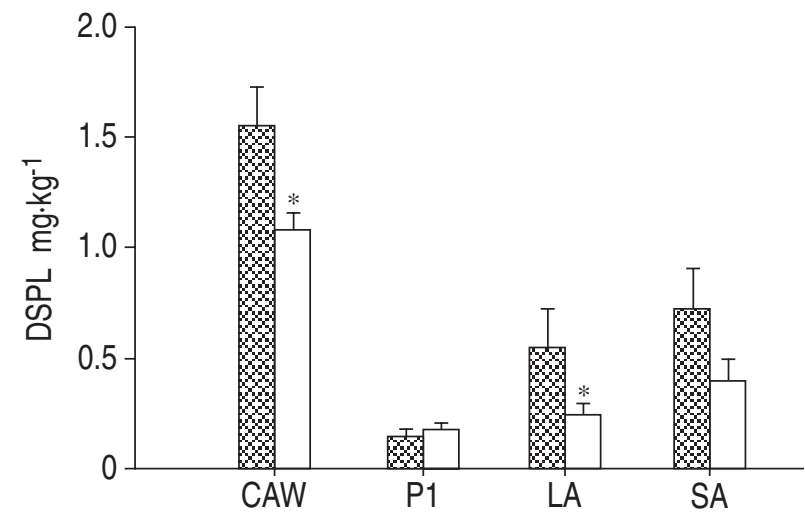

Fig. 3. - Disaturated phospholipid (DSPL) pool sizes in the subfractions and the crude alveolar wash (CAW) samples obtained from sham-

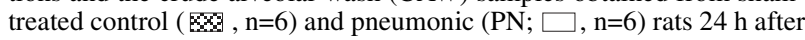
intratracheal instillation of sterile phosphate-buffered saline or Pseudomonas aeruginosa, respectively. P1 is the subfraction containing primarily cellular debris. The total DSPL content of CAW, as well as the DSPL content of the large aggregate (LA) subfraction, was significantly lower in PN rats than in control rats $(*: \mathrm{p}<0.05)$. SA: small aggregate surfactant subfraction. Values are expressed as means \pm SEM.

determined. In general, the PN group had fewer phospholipids than the control group in CAW $(4.1 \pm 0.3$ versus $6.3 \pm$ $\left.0.6 \mathrm{mg} \cdot \mathrm{kg}^{-1}\right)$, LA $\left(1.1 \pm 0.3\right.$ versus $\left.2.2 \pm 0.3 \mathrm{mg} \cdot \mathrm{kg}^{-1}\right)$, and SA $\left(1.5 \pm 0.2\right.$ versus $\left.2.6 \pm 0.4 \mathrm{mg} \cdot \mathrm{kg}^{-1}\right)$ fractions, although, in the P1 fraction, PN animals had a significantly higher phospholipid pool size than the control animals $(1.2 \pm 0.2$ versus $0.4 \pm 0.1 \mathrm{mg} \cdot \mathrm{kg}^{-1}$, pð0.05). Since some of this total phospholipid may be due to debris from lysed bacteria, particularly in the P1 fraction, DSPL levels were also quantified in each fraction (fig. 3). These data show that CAW samples obtained from the PN group contained significantly less DSPL than that from the control animals (po 0.05 ) and there was also significantly less DSPL in the LA fraction (pð0.05). In contrast to the total phospholipid analysis, however, the DSPL data showed no significant differences between PN and control groups for the P1 fraction, suggesting that the differences in the phospholipid pool sizes for this fraction were not due to functional surfactant components.

Measurements of the surfactant-associated proteins SP$\mathrm{A}$ and SP-B revealed no significant differences between groups (table 2). Similarly, no differences existed in the relative amounts of the individual surfactant phospholipids between groups (table 2). However, the ratios of phosphatidylglycerol (PG):phosphatidylinositol (PI) + phosphatidylserine (PS) and phosphatidylcholine (PC):PI+PS were significantly lower in the PN animals than in control animals $(\mathrm{p}<0.05)$. The total protein content recovered from the CAW of the PN group was significantly greater (81.8 \pm

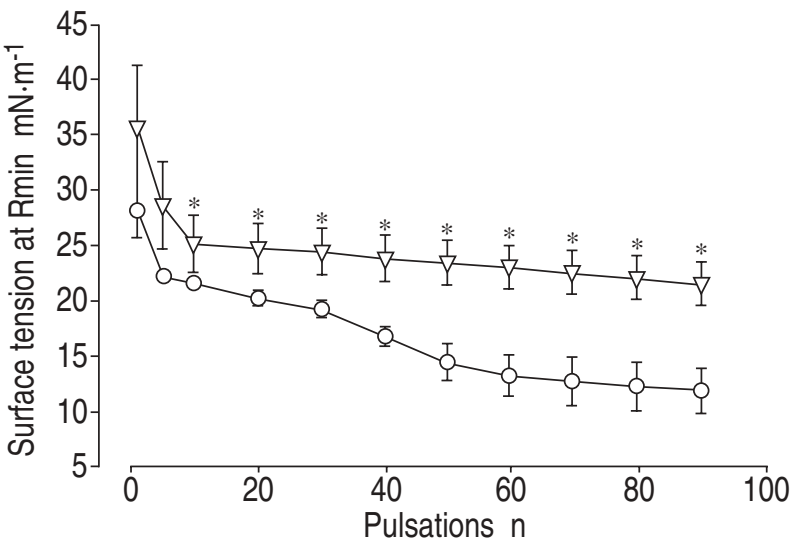

Fig. 4. - Surface activity at minimum bubble radius ( $\mathrm{Rmin}$ ) for large aggregates (LA) isolated from crude alveolar wash (CAW) of shamtreated control $(\mathrm{O}, \mathrm{n}=6)$ and pneumonic $(\mathrm{PN} ; \nabla, \mathrm{n}=6)$ rats. LA were analysed at a concentration of $1 \mathrm{mg}$ phosphoplipid $\cdot \mathrm{mL}^{-1}$ on a pulsating bubble surfactometer. Following 10 pulsations, values at each time point were significantly higher in PN animals than in control rats $(*: \mathrm{p}<0.05)$. Values are expressed as means \pm SEM.

$\left.13.7 \mathrm{mg} \cdot \mathrm{kg}^{-1}\right)$ than from the control group $(40.2 \pm 11.8$ $\left.\mathrm{mg} \cdot \mathrm{kg}^{-1}\right)(\mathrm{p}<0.05)$.

Functional analysis of the recovered surfactant revealed that LA obtained from control rats reduced surface tension at $R$ min to significantly lower values $(\mathrm{p}<0.05)$ than did LA isolated from rats in the PN group (fig. 4). Significant differences in surface tension measurements at Rmin were apparent even after 10 pulsations and were more marked after 90 pulsations. Comparisons between groups revealed no significant differences in surface tension at adsorption (after zero pulsations) or at the maximal bubble radius (data not shown).

\section{Bacteriological assessment}

When corrected for body weight, the lungs isolated from rats in the PN group ( $491 \pm 30 \mathrm{mg} \cdot 100 \mathrm{~g}^{\text {body weight }}{ }^{-1}$ ) weighed significantly more than the lungs isolated from control rats $\left(351 \pm 17 \mathrm{mg} \cdot 100 \mathrm{~g}\right.$ body weight $\left.{ }^{-1}\right)(\mathrm{p}<0.05)$. Similarly, after the addition of $3 \mathrm{~mL}$ buffer and subsequent homogenization, a significantly greater volume of lung homogenate was obtained from rats in the PN group $(4.6 \pm 0.2 \mathrm{~mL})$, compared with the control group $(3.7 \pm 0.1$ $\mathrm{mL})(\mathrm{p}<0.05)$.

Samples of lung homogenate isolated from the PN group grew visible colonies of $P$. aeruginosa $\left(7.6 \pm 2.7 \times 10^{4}\right.$ $\left.\mathrm{cfu} \cdot \mathrm{mL}^{-1}\right)$. No colonies of pseudomonas were identified on the plates inoculated with lung homogenate isolated from control rats. Although bacterial colonization and infection

Table 2. - Surfactant-associated protein levels and phospholipid composition of surfactant obtained from sham-treated control and pneumonic (PN) rats $24 \mathrm{~h}$ after intratracheal instillation of sterile phosphate-buffered saline and Pseudomonas aeruginosa, respectively

\begin{tabular}{lcccccccccc}
\hline Group (n) & $\%$ PC & \%PG & \%SM & \%PE & \%LPC & \%PI+PS & PC/PI+PS & PG/PI+PS & $\begin{array}{c}\text { SP-A } \\
\mu g \cdot k g-1\end{array}$ & $\begin{array}{c}\text { SP-B } \\
\mu \mathrm{g} \cdot \mathrm{kg}-1\end{array}$ \\
\hline Sham (6) & $72.5 \pm 3.0$ & $3.5 \pm 0.5$ & $14.3 \pm 3.2$ & $1.5 \pm 0.3$ & $4.2 \pm 0.3$ & $4.0 \pm 0.1$ & $18.1 \pm 0.7$ & $0.9 \pm 0.1$ & $75.8 \pm 16.3$ & $4.1 \pm 0.5$ \\
PN (6) & $73.6 \pm 2.2$ & $2.9 \pm 0.6$ & $12.1 \pm 1.3$ & $1.0 \pm 0.2$ & $3.9 \pm 0.7$ & $6.5 \pm 0.9$ & $12.5 \pm 1.7 *$ & $0.5 \pm 0.1 *$ & $59.7 \pm 10.8$ & $4.4 \pm 0.4$ \\
\hline
\end{tabular}

Values are means \pm SEM. \%: percentage of total phospholipid pool. PC: phosphatidylcholine; PG: phosphatidylglycerol; SM: sphinogomyelin; PE: phosphatidylethanolamine; LPC: lysophosphatidylcholine; PI+PS: phosphatidylinositol+phosphatidylserine; SP-A: surfactant-associated protein A; SP-B: surfactant-associated protein B. *: $\mathrm{p}<0.05$ versus control. 
of lung tissue was evident by gross inspection, only a small percentage $(0.07 \pm 0.02 \%)$ of the initial bacterial input $\left(10.1 \pm 1.3 \times 10^{7} \mathrm{cfu} \cdot \mathrm{mL}^{-1}\right)$ was recovered in the lung homogenate at $24 \mathrm{~h}$.

Control experiments were conducted in which lungs were homogenized immediately after inoculation with pseudomonas. Similarly, the same pseudomonas inoculum was added directly to the homogenate of noninfected lungs. In both cases, approximately $50 \%$ of the initial bacterial input was recovered, indicating that the low recovery at $24 \mathrm{~h}$ in the PN group was primarily due to host clearance.

\section{Discussion}

P. aeruginosa is the infectious organism responsible for most cases of nosocomial pneumonia [1]. Presently, the treatment for this disorder consists primarily of antibiotic administration, although typical antibiotic combinations have had little effect on patient morbidity and mortality [1, 2].

In this study, a clinically relevant rat model of acute pseudomonas pneumonia was established, characterized by physiological alterations similar to those observed in patients with this illness. These impairments included disturbances in gas exchange reflected by arterial hypoxaemia and a significant elevation in $\mathrm{PA}-\mathrm{a}, \mathrm{O}_{2}$, elevated respiratory rates and a decrease in lung compliance, reflected by changes in pressure-volume curves. MAP was also slightly reduced in the infected animals, and although this reduction was statistically significant and has been shown in other animal models of pneumonia [31, 32], the actual pressures measured in these animals remained essentially normotensive and did not result in a hypoperfused state. Other changes characteristic of the bacterial infection induced in these animals included elevated arterial lactate levels, leukopenia and morphological evidence of bronchopneumonia with airspaces filled with abundant polymorphonuclear cells. These latter morphological changes, together with the recovery of $P$. aeruginosa bacteria from lung tissue at the time of killing, confirm the presence of pneumonia in these animals and are very similar to the changes seen in patients with bronchopneumonia.

Associated with the observed physiological changes, and no doubt contributing to these changes, were the observed alterations in the endogenous surfactant system. Previous studies analysing BAL samples obtained from patients with pneumonia $[16,33]$ noted a decrease in phosphatidylcholine concentrations. Similar observations were noted in the present study, which saw a decrease in the lavage-obtained DSPL pool of pneumonia animals, of which dipalmitylphosphatidylcholine is the major component. KING et al. [34] reported a $33 \%$ decrease in total surfactant phospholipid concentrations in adult baboons following hyperoxia and $P$. aeruginosa-induced lung injury. Similarly, TAHVANEN and Hallman [35] observed a 52$67 \%$ decrease in total surfactant phospholipids following endotracheal injection of endotoxin in guinea-pigs. One limitation of these previous studies, however, was the technique used to sample the alveolar space. For example, BAL samples only reflect changes occurring in the area from which material was obtained and are only capable of measuring surfactant phospholipid concentrations rather than total pool sizes. The whole lung lavage method used in the present study permitted a very accurate measurement of total surfactant pool sizes. The results confirmed that, by the observed decrease in DSPL levels (the major components of surfactant), the total quantity of functional alveolar surfactant was decreased in PN animals compared with control animals.

An additional novel finding in the present study was that there was a decrease in the LA surfactant fraction in the PN animals, which was probably responsible for the observed changes in the total surfactant pool size. This was an important finding as LA forms of surfactant have been shown to be primarily responsible for surface tension reduction at the air-liquid interface [21]. Indeed, reports from experimental animal models of acute lung injury reflecting the clinical disease of ARDS have also reported a relative decrease in the surfactant LA fraction, as well as an increase in the SA fraction [21, 22, 36]. In these studies, the aggregate changes were shown to contribute directly to the decreased lung compliance and decreased $\mathrm{Pa}, \mathrm{O}_{2}$ values observed in the injured animals [17, 22]. Based on these observations, it was speculated that the decrease in the proportion of LA observed in the PN animals contributed to the abnormal physiology demonstrated in these animals.

In addition to the decreased quantity of the LA fraction recovered in the PN animals, there was a significant impairment in the function of the LA fractions. LA isolated from the PN rats did not reduce surface tension to the levels observed for LA isolated from control rats. This finding was consistent with functional assessments of LA isolated from animals with acute lung injury [17, 36]. Although previous functional impairments of BAL samples obtained from patients with pneumonia have been demonstrated [16,33], this study has shown that it is the LA fraction in particular that is responsible for the surfactant dysfunction in pneumonia.

The potential mechanisms responsible for this loss of functional activity of the endogenous surfactant system may be several-fold. Firstly, the inhibitory effects of bacterial endotoxin and its lipopolysaccharide constituents on pulmonary surfactant have previously been shown to be important in in vitro studies [33]. Secondly, it is likely that the leakage of plasma proteins into the alveolar space [37] contributed to surfactant inhibition in PN rats, as this phenomenon has previously been shown to contribute to surfactant dysfunction [17] in animal models of acute lung injury. Moreover, plasma protein leakage into the alveolar space of PN animals was confirmed by an observed increase in the total protein content of CAW obtained from these rats. This also probably reflects the protein content of surfactant LA fractions in these two groups. These LA preparations were tested for surface activity at a total phospholipid concentration of $1 \mathrm{mg} \cdot \mathrm{mL}^{-1}$, but measurements of DSPL revealed that the LA fraction of PN animals contained a smaller percentage of phospholipids in the disaturated form than did the LA fractions of the control animals. Although this difference did not reach statistical significance, the lower quantity of functionally active DSPL in the PN LA samples may have contributed to the surfactant dysfunction observed in this group. A combination of a higher quantity of protein and a lower quantity of DSPL in the PN LA fractions could explain the abnormal 
functional activity of the isolated LA forms obtained from $\mathrm{PN}$ rats.

Other mechanisms may also have resulted in the decreased quantity of surfactant LA forms in the PN rats. While LA have been shown to be the metabolic precursors of SA and are continuously being converted into SA in the normal alveolar environment, under certain conditions (i.e. lung injury) this conversion process has been shown to be increased $[17,21]$. For example, it has been suggested that in acute lung injury, an increase in protease activity results in an increased conversion of LA into SA and, therefore, a decrease in the size of the LA pool [17, $22,36]$. In this study, a similar process was probably occurring, although no increase in the SA pool size was observed. This may well have been due to an increase in SA uptake by alveolar type II cells, or an increase in clearance of SA forms by alveolar macrophages, a route of clearance of endogenous SA forms demonstrated in normal lungs [17]. Further studies are required to elucidate fully the mechanisms responsible for the changes observed in the aggregate pool sizes in these animals.

In contrast to previous observations in patients with pneumonia, no significant changes in the proportion of individual surfactant phospholipids were observed. Previous human studies reported decreased levels of PC and PG and increased levels of sphingomyelin and PI [16]. A potential reason for this discrepancy may be that these alterations are either species-specific or pathogen-specific, as the human studies involved a variety of different infectious agents [16]. Despite these discrepant results, changes were observed in phospholipid ratios. While this finding was consistent with previous reports of pneumonia $[34,38]$, it is of questionable functional importance as previous studies of acute lung injury have provided no evidence indicating that changes in phospholipid composition changes contribute significantly to lung dysfunction $[17,36]$.

Although phospholipid composition was altered in PN animals, there were no significant differences noted in surfactant-associated protein levels, again a finding in con-trast to human studies. This discrepancy could be due to the specific pathogen being studied. While one study de-monstrated increased SP-A levels in BAL samples from patients with Pneumocystis carinii pneumonia [39], other studies have shown decreased SP-A levels in patients with bacterial pneumonia $[15,16]$. It should be noted that while there were no differences observed in the total quantity of recovered SP-A and SP-B between the $\mathrm{PN}$ and control animals in the present study, the function of these proteins was not assessed. Further studies addressing this issue may provide additional information that will aid our un-derstanding of the role played by these proteins in the course of bacterial infection.

The similarities of the surfactant alterations in both pneumonia and acute lung injury have been discussed. These observations may reflect the general inflammatory response associated with both conditions. It is also interesting to note that $70 \%$ of patients dying from ARDS were noted to have pneumonia upon post mortem examination [40]. These observations, and indeed the overall relevance of the present study, reflect the role of the pulmonary surfactant system in host defence. Traditionally, the major function of pulmonary surfactant has been assumed to be biophysical, namely lowering surface ten- sion to maintain alveolar stability and prevent alveolar collapse. If the surfactant system is altered, the consequences are decreased lung compliance, alveolar oedema and arterial hypoxaem-ia. More recently, however, several in vitro studies have implicated surfactant as an important component of the inflammatory and infectious response, regulating the re-lease of inflammatory mediators in the airspace, as well as enhancing the antibacterial activities of alveolar macrophages. In vivo, however, the role of surfactant in this ca-pacity is unknown, although the current model may prove valuable in assessing the role of surfactant in maintaining the integrity of host defence over the course of pneumonia.

In summary, a rat model of an acute pulmonary infection with Pseudomonas aeruginosa was developed, with the resulting pathophysiology typical of that observed in patients with bacterial pneumonia. Alterations to the endogenous surfactant system were also observed and these changes have been shown to contribute to the lung dysfunction associated with this condition. As antibiotic therapy is not always effective in the treatment of pneumonia and since the surfactant system has a role in the pathophysiology of this disorder, exogenous surfactant administration represents a potential therapeutic strategy, both from a physiological standpoint and in host defence. This model will ultimately serve as a valuable tool in assessing the efficacy of this potential treatment strategy.

Acknowledgements: The authors would like to thank W. Hull for technical assistance in the SP-A and SP-B analysis, F. Possmayer for the use of the pulsating bubble surfactometer and R. Veldhuizen for his helpful discussion. Additional thanks go to the Microbiology Dept at St. Joseph's Health Centre for technical assistance and helpful discussion concerning bacteriological procedures.

\section{References}

1. Pare P, Fraser R. Infectious diseases of the lung. In: Synopsis of Diseases of the Chest. Philadelphia, PA, W.B. Saunders, 1983; pp. 254-357.

2. Johnson C, Finegold S. Pyogenic bacterial pneumonia, lung abcess, and empyema. In: Murray J, Nadel J, eds. Textbook of Respiratory Medicine. Philadelphia, PA, W.B. Saunders, 1988; pp. 803-855.

3. Jobe A, Ikegami M. Surfactant for the treatment of respiratory distress syndrome. Am Rev Respir Dis 1987; 136: $1256-1275$.

4. Thomassen MJ, Antal JM, Connors MJ, Meeker DP, Wiedemann HP. Characterization of Exosurf (Surfactant)-mediated suppression of stimulated human alveolar macrophage cytokine responses. Am J Respir Cell Mol Biol 1994; 10: 399-404.

5. Thomassen MJ, Meeker DP, Antal JM, Connors MJ, Wiedemann HP. Synthetic surfactant (Exosurf) inhibits endotoxin-stimulated cytokine secretion by human alveolar macrophages. Am J Respir Cell Mol Biol 1992; 7: 257260.

6. Geertsma MF, Teeuw WL, Nibbering PH, Van Furth R. Pulmonary surfactant inhibits activation of human monocytes by recombinant interferon- $\delta$. Immunology 1994; 82: 450-456.

7. Borron P, Veldhuizen RA, Lewis JF, et al. Surfactant associated protein A inhibits human lymphocyte proliferation and IL-2 production. Am J Respir Cell Mol Biol 
1996; 15: 115-121.

8. Van Golde LMG. Potential role of surfactant proteins A and $\mathrm{D}$ in innate lung defense against pathogens. Biol Neonate 1995; 67: 2-17.

9. Hoffman RM, Claypool WD, Katyal SL, Singh G, Rogers RM, Dauber JH. Augmentation of rat alveolar macrophage migration by surfactant protein. Am Rev Respir Dis 1987; 135: 1358-1362.

10. Wright JR, Youmans DC. Pulmonary surfactant protein A stimulates chemotaxis of alveolar macrophage. Am J Physiol 1993; 264: L338-L344.

11. Weissbach S, Neuendank A, Pettersson M, Schaberg T, Pison U. Surfactant protein A modulates release of reactive oxygen species from alveolar macrophages. $A m J$ Physiol 1994; 267: L660-L666.

12. Van Iwaarden JF, Shimizu H, Van Golde PH, Voelker DR, Van Golde LM. Rat surfactant protein D enhances the production of oxygen radicals by rat alveolar macrophages. Biochem J 1992; 286: 5-8.

13. Manz-Keinke H, Plattner H, Schlepper-Schafer J. Lung surfactant protein A (SP-A) enhances serum-independent phagocytosis of bacteria by alveolar macrophages. Eur $J$ Cell Biol 1992; 57: 95-100.

14. Pikaar JC, Voorhout WF, Van Golde LMG, Verhoef J, Van Strijp JA, Van Iwaarden JF. Opsonic activities of surfactant proteins $A$ and $D$ in phagocytosis of Gram-negative bacteria by alveolar macrophages. J Infect Dis 1995; 172: 481-489.

15. Baughman RP, Sternberg RI, Hull W, Buchsbaum JA, Whitsett J. Decreased surfactant protein A in patients with bacterial pneumonia. Am Rev Respir Dis 1993; 147: 653-657.

16. Gunther A, Siebert C, Schmidt R, et al. Surfactant alterations in severe pneumonia, acute respiratory distress syndrome, and cardiogenic lung edema. Am J Respir Crit Care Med 1996; 153: 176-184.

17. Lewis JF, Jobe AH. Surfactant and the adult respiratory distress syndrome. Am Rev Respir Dis 1993; 147: 218-233.

18. Seeger W, Pison U, Buchhorn R, Obertacke U, Joka T. Surfactant abnormalities and adult respiratory failure. Lung 1990; 168: 891-902.

19. Holm BA, Matalon S. Role of pulmonary surfactant in the development and treatment of adult respiratory distress syndrome. Anesth Analg 1989; 69: 805-818.

20. Malloy J, McCaig L, Veldhuizen R, et al. Alterations of the endogenous surfactant system in septic adult rats. $A m$ J Respir Crit Care Med 1997; 156: 617-623.

21. Veldhuizen RA, Ito Y, Marcou J, Yao L, McCaig L, Lewis JF. Effects of lung injury on pulmonary aggregate conversion in vivo and in vitro. Am J Physiol 1997; 272: L872L878.

22. Lewis JF, Veldhuizen R, Possmayer F, et al. Altered alveolar surfactant is an early marker of acute lung injury in septic adult sheep. Am J Respir Crit Care Med 1994; 150: 123-130.

23. Bligh EG, Dyer WJ. A rapid method of total lipid extraction and purification. Can J Biochem Physiol 1959; 37:
911-917.

24. Mason RJ, Nellenbogen J, Clements JA. Isolation of disaturated phosphatidylcholine with osmium tetroxide. $J$ Lipid Res 1978; 17: 281-284.

25. Duck-Chong CG. A rapid sensitive method for determining phospholipid phosphorus involving digestion with magnesium nitrate. Lipids 1979; 14: 492-497.

26. Lowry OH, Rosebrough NJ, Farr AL, Randall RJ. Protein measurement with the Folin reagent. J Biol Chem 1951; 193: 265-275.

27. Enhorning G. Pulsating bubble technique for evaluating pulmonary surfactant. J Appl Physiol 1977; 43: 198-203.

28. Nogee LM, Wispe JR, Clark JC, Weaver TE. Increased expression of pulmonary surfactant proteins in oxygenexposed rats. Am J Respir Cell Mol Biol 1991; 4: 102 107.

29. Subramaniam S, Whitsett JA, Hull W, Gairola CG. Alterations of pulmonary surfactant proteins in rats chronically exposed to cigarette smoke. Toxicol Appl Pharmacol 1996; 140: 274-280.

30. Dittmer J, Lester R. A simple, specific spray for the detection of phospholipids on thin-layer chromatograms. J Lipid Res 1964; 5: 126-127.

31. Hanly P, Light RB. Lung mechanics, gas exchange, pulmonary perfusion, and hemodynamics in a canine model of acute pseudomonas pneumonia. Lung 1987; 165: 305322.

32. Keenan RJ, Todd TR, Girotti MJ. Experimental gramnegative pneumonia produce a hyperdynamic septic profile. Circ Shock 1987; 22: 303-309.

33. Brogden KA. Changes in pulmonary surfactant during bacterial pneumonia. Antonie van Leeuwenhoek 1991; 59: $215-223$.

34. King RJ, Coalson JJ, Seidenfeld JJ, Anzueto AR, Smith $\mathrm{DB}$, Peters JI. $\mathrm{O}_{2}^{-}$and pneumonia-induced lung injury II. Properties of pulmonary surfactant. J Appl Physiol 1989; 67: 357-365.

35. Tahvainen J, Hallman M. Surfactant abnormality after endotoxin-induced lung injury in guinea-pigs. Eur J Respir Dis 1987; 71: 250-258.

36. Lewis JF, Ikegami M, Jobe AH. Altered surfactant function and metabolism in rabbits with acute lung injury. $J$ Appl Physiol 1990; 69: 2303-2310.

37. Pittet JF, Mackersie RC, Martin TR, Matthay MA. Biological markers of acute lung injury: prognostic and pathogenetic significance. Am J Respir Crit Care Med 1997; 155: 1187-1205.

38. Sachse K. Changes in the relative concentrations of surfactant phospholipids in young pigs with experimental pneumonia. J Vet Med 1989; 36: 385-390.

39. Phelps DS, Rose RM. Increased recovery of surfactant protein A in AIDS-related pneumonia. Am Rev Respir Dis 1991; 143: 1072-1075.

40. Johanson W Jr. Bacterial infection in adult respiratory distress syndrome. In: Zapol W, Lemaire F, eds. Adult Res-piratory Distress Syndrome. New York, Marcel Dekker, 1991; pp. 77-90. 